\title{
Adherence to ketoacids/essential amino acids-supplemented low protein diets and new indications for patients with chronic kidney disease
}

\author{
Denis Fouque ${ }^{1,14^{*}}$ (D) Jing Chen ${ }^{2}$, Wei Chen ${ }^{3}$, Liliana Garneata ${ }^{4}$, SJ Hwang ${ }^{5}$, Kamyar Kalantar-Zadeh ${ }^{6,7}$, \\ Joel D. Kopple ${ }^{8,9}$, William E. Mitch ${ }^{10}$, Giorgina Piccoli ${ }^{11}$, Vladimir Teplan ${ }^{12}$ and Philippe Chauveau ${ }^{13}$
}

\begin{abstract}
Background: Low protein diets (LPD) have long been prescribed to chronic kidney disease patients with the goals of improving metabolic abnormalities and postpone the start of maintenance dialysis.

Methods: We reviewed the recent literature addressing low protein diets supplemented with ketoacids/essential aminoacids prescribed during chronic kidney disease and their effects on metabolic, nutritional and renal parameters since 2013.

Results: We show new information on how to improve adherence to these diets, on metabolic improvement and delay of the dialysis needs, and preliminary data in chronic kidney disease associated pregnancy. In addition, data on incremental dialysis have been reviewed, as well as potential strategies to reverse protein energy wasting in patients undergoing maintenance dialysis.

Conclusion: These recent data help to better identify the use of low protein diets supplemented with ketoacids/essential aminoacids during chronic kidney disease.
\end{abstract}

Keywords: Protein, Ketoacid, Keto-analog, Low protein diet, Kidney disease, Wasting, Dialysis

\section{Background}

Maintenance dialysis is a burden for the global health systems globally and is growing at an unprecedented rate. A recent analysis of the prevalence of end stage renal disease led to the conclusion that the prevalence of maintenance dialysis has grown more rapidly during the last two decades than predicted [1]. Efforts to delay the progression to end stage renal disease (ESRD) mainly rely on control of blood pressure and diabetes. Unfortunately, in many countries nephrologists generally do not examine CKD patients until dialysis is imminent and they have few options for delaying the time to dialysis. However, increasing the time until transition to dialysis therapy may improve patient's

\footnotetext{
* Correspondence: denis.fouque@chu-lyon.fr

${ }^{1}$ UCBL, Centre Hospitalier Lyon-Sud, University Lyon, Carmen, Cens, F-69622 Lyon, France

${ }^{14}$ Department Nephrology, Centre Hospitalier Lyon Sud, Chemin du grand revoyet, 69495 Pierre Bénite, France

Full list of author information is available at the end of the article
}

quality of life and can reduce the financial strain on the healthcare system. Consequently, postponing dialysis initiation should receive a high priority in majority of patients with advanced CKD. In fact, there is evidence that many patients will be able to postpone the transition to dialysis, reportedly, more than $60 \%$ of all CKD patients can experience a persistently low GFR (i.e., below $25 \mathrm{ml} / \mathrm{min} /$ $1.73 \mathrm{~m}^{2}$ ) during the two years prior to initiation of dialysis $[2,3]$. In short, there is opportunity to reduce the drivers of chronic kidney disease, including poorly controlled hypertension and decreased symptoms of uremia using a low protein diet supplemented with ketoanalogues in countries where these agents are available and including dietary salt restriction $[4,5]$. In jurisdictions without approved ketoacids such as the United States or Canada, essential amino acids can be used instead. These strategies were concisely reviewed in 2013 [6], therefore this review will focus on evidence for efficacy that has become 
available since. In addition, it should be recalled that the currently available ketoanalogues (KA) preparations are marketed with other essential amino acids (EAA), which will be referred as KA/EAA below in text.

\section{How to improve adherence and select patients to a KA/EAA-supplemented low protein diet}

The general approach to treatment of patients with low or supplemented very low protein diets often results in a tug of war between the patient's will to comply vs nutritional temptations and deeply rooted food habits. Consequently, doctors should consider that to attain good compliance it is advisable to set goals of adherence - the conscious decision of the patient to stick with a therapy - as a therapeutic goal. To overcome this often frustrating situation, Piccoli et al. [7] sought to identify factors that influence patient adherence. They investigated implementation of a simplified low-protein, KA/EAA supplemented diet as part of the routine work-up of CKD patients. Patients with CKD stages 4 to 5 or patients with CKD stage 3 and rapid progression and/or a refractory nephrotic syndrome were offered SLPD ( $0.6 \mathrm{~g}$ protein $/ \mathrm{kg} /$ day). The endpoint was defined as at least six months of follow-up on the diet and the results were analysed by comparing demographic and health parameters among patients following the diet for less than one month vs. those who followed the restricted diet for up to six months. The results indicated that successful adherence was unpredictable a priori, as no medical or social parameters were identified as indicative of continuous adherence to the SLPD [7]. Renal nutrition education has also been reported to improve adherence to LPD in a Brazilian randomized controlled trial [8].

Another recent study [9] from the same group addressed the compliance issue in 185 patients given KA/EAA supplemented LPD ( $0.6 \mathrm{~g}$ protein $/ \mathrm{kg} /$ day supplemented with 1 tablet per $10 \mathrm{~kg} \mathrm{BW/day)} \mathrm{vs} 122$ patients prescribed a LPD with the same protein intake and commercially available protein-free food. Adherence was assessed from food questionnaires, $24 \mathrm{~h}$ urine urea collection and tablet counts. Patients who chose SLPD were younger and had significantly lower GFR values and higher levels of proteinuria. After six months, the median protein intake was $0.7 \mathrm{~g} / \mathrm{kg} \mathrm{BW} / \mathrm{d}$ in both groups. Albumin and total protein levels were stable at six and twelve months. Of note, even after GFR fell below $15 \mathrm{ml} / \mathrm{min}$, the diet was still followed by $59 \%$ patients at six months and $32 \%$ at twelve months. At one year, all patients had reduced their albuminuria and degree of acidemia. Interestingly the two low protein diets were comparable in cost. Thus, compared to an "early start" dialysis (i.e., when GFR is $>10 \mathrm{ml} / \mathrm{min}$ ), this dietary approach of an KA/EAA supplemented $0.6 \mathrm{~g}$ protein $/ \mathrm{kg} /$ day diet resulted in substantial financial savings [10].

A landmark trial for the therapy with supplemented low protein diet by Garneata et al. has been recently published
[11]. These investigators conducted a prospective, open, parallel, randomized controlled study comparing vegetarian VLPD $(0.3 \mathrm{~g} / \mathrm{kg} /$ day $)$ supplemented with KA/EAA, 1 tablet $/ 5 \mathrm{~kg} \mathrm{BW}$ with LPD $(0.6 \mathrm{~g} / \mathrm{kg} /$ day $)$ in non-diabetic patients with a stable eGFR below $30 \mathrm{ml} / \mathrm{min} / 1.73 \mathrm{~m}^{2}$. The study had a three-step enrolment procedure: patients were asked if they would be willing to follow a low protein diet, vegetarian if necessary; only those who were willing to do so were included into a three month run-in period with a low protein diet. 1,413 patients were assessed for eligibility and $42 \%$ of them declined to consider a vegetarian diet. Dietary compliance was controlled monthly, and only patients who followed the diet were finally enrolled and followed for up to 18 months. In the run-in phase, another $44 \%$ dropped out, mainly for non-adherence to the LPD. Thus only $14 \%$ (207) of the patients initially eligible entered the intervention period. The primary composite endpoint was initiation of dialysis or a reduction in the initial eGFR by more than $50 \%$. The SVLPD resulted in a significant delay of time to dialysis: while only $13 \%$ in the SVLPD group reached the primary endpoint, $42 \%$ did in the nonsupplemented LPD group. Mean time to event was longer in the SVLPD group with 57 (55-59) weeks vs 47 (43-50) weeks in the control group $(p<0.001)$. The decline in eGFR was slower in SVLPD group as compared to LPD with a median difference between groups of 3.2 [2.6-3.8] $\mathrm{mL} / \mathrm{min}$. At 15 months, only the SVLPD group experienced a significant reduction of serum urea (120 [84-132] vs 167 [136$273] \mathrm{mg} / \mathrm{dL}$ ) and serum phosphorus (4.4 [4.1-4.8] vs 5.5 [4.3-6.9,] $\mathrm{mg} / \mathrm{dl})$ while serum calcium (4.5 [4.4-4.7] vs 3.9 (3.9-4.0), $\mathrm{mg} / \mathrm{dL}$ ) and serum bicarbonate increased significantly $(23.9$ [21.5-25.1] vs 17.3 [15.3-18.7] $\mathrm{mEq} / \mathrm{L})$. The adjusted "number needed to treat" (NNT) to avoid the primary composite endpoint was 4.0 (3.9-4.4). The adjusted NNT to avoid dialysis initiation was 22.4 (21.5-25.1), but decreased to $2.7(2.6-3.1)$ when only patients with eGFR $<20 \mathrm{~mL} / \mathrm{min}$ were retained in analysis. No significant changes in nutritional status and no drug-related adverse reactions were noted. Elderly ( $>65$ years) and young active patients $(<45$ years) seemed to more easily accept the dietary intervention. Strong family/social support and, being already vegan or vegetarian were also identified as supportive characteristics [11]. Thus, adherence to a SVLPD can be achieved only if a good selection strategy is made and test periods are performed. Overall however, only $30 \%$ of the pre-selected patients correctly achieved the very low protein intake reduction.

\section{New features of low protein diets in chronic kidney disease and dialysis Pregnancy}

It has long been feared that provision of a LPD to pregnant patients with CKD could interfere with growth of the foetus. Piccoli et al. [12]. assessed the effect of a 
vegan-based LPD supplemented with KA/EAA on fetal growth in pregnant women with CKD. In an open, interventional study of pregnant patients with stage 3-5 CKD or with proteinuria $(>1 \mathrm{~g} / \mathrm{d}$ in the first trimester or the presence of nephrotic-range proteinuria at any time), positive outcomes were observed during an evaluation from 2000 to 2012. Specifically, the patients treated with a LPD (0.6-0.8 g/kg per day) supplemented with KA/ EAA plus 1 to 3 protein-unrestricted meals/week maintained a good nutritional status. In comparison to pregnant CKD women who did not receive LPD for various reasons (late referral, stable disease, previous nutritional problems), the women treated with protein-restrictedKA/EAA diets had fewer new-borns that were "small for gestational age" (i.e., 3 of 21 pregnancies) compared to those fed ad libitum (i.e., 7 of $16 ; p=0.05$ ) [12]. The mothers and children were followed for periods of six months to ten years and those treated with LPD-KA/EAA regimen had lower rates of hospitalization even though the prevalence of children below the third growth percentile were similar to events in the mothers fed ad libitum. These clinical outcomes certainly deserve to be tested in larger multicentre studies.

\section{Maturating arteriovenous fistulas}

Can low protein diets help expanding time until initiation of dialysis? The best timing of dialysis initiation has long been a matter of debate and the IDEAL study [13] has proven that an early dialysis start may be hazardous. In addition, too often nephrologists do not become involved in the care of CKD patients until dialysis is imminent. Besides obvious advantages of an earlier referral of CKD patients to the nephrologist, late referrals may even interfere with the patients being introduced properly to dialysis (e.g., inadequate time to create a functional arteriovenous access or the option to be trained for peritoneal dialysis). Duenhas et al. [14] prospectively enrolled 21 patients who were scheduled to start haemodialysis based on serum urea reached $\geq 175 \mathrm{mg} / \mathrm{dl}$ and the creatinine clearance was $\leq 12 \mathrm{ml} / \mathrm{min}$. These patients were advised to consume a "very low protein diet" (VLPD; $0.3 \mathrm{~g} / \mathrm{kg} /$ day) consisting mainly of vegetable proteins and KA/EAA for 30 days to allow maturation of arteriovenous access and/or training for peritoneal dialysis. Ten of these patients $(47.3 \%)$ developed a matured permanent dialysis access within a mean follow up of $83.3 \pm 58.2$ days. Serum concentration of urea dropped significantly from a mean of $175.3 \pm 48.3 \mathrm{mg} / \mathrm{dl}$ to $109.0 \pm 25.8 \mathrm{mg} / \mathrm{dl}(p<0.001)$. Serum calcium and phosphorus were improved while body mass index, muscle mass and other biochemical parameters including serum albumin were unchanged. The authors conclude that a very low protein diet supplemented with KA/EAA can maintain stable or even improved metabolic status in patients with very low renal function with no deterioration in protein-energy status until initiation of dialysis via a permanent dialysis access fistula [14]. These findings are of major clinical and public health importance because recent guidelines [15] call for an "intent-to-defer" as more efficacious compared to an "intent-to-start-early" approach in planning for the initiation of chronic dialysis in adults with an estimated GFR (eGFR) of less than $15 \mathrm{ml} / \mathrm{min} / 1.73 \mathrm{~m}^{2}$. Authors of this consensus paper emphasize that better health-related quality of life and fewer burdens associated with earlier initiation of dialysis without clinical indications should be the goal, especially because some complications of uraemia may be avoided. In addition, this may help containing dialysis expenses as well [16].

\section{Incremental dialysis}

Incremental dialysis should be discussed when searching for alternate dialysis initiation models. Indeed, the IDEAL trial [13] clearly showed that an early start of hemodialysis was of no benefit to patients, and as a consequence, an interest in incremental hemodialysis $[17,18]$ has recently arisen. This consists of one or two weekly hemodialysis sessions, based on the patient's residual renal function and degree of metabolic abnormalities. As renal function decreases and/or metabolic disorders related to kidney failure increase, the patients dialysis dose increases until they begin a full thrice-weekly dialysis schedule. In a prospective non-randomized study of 85 Chinese MHD patients, after one year, those who were receiving twice dialysis sessions weekly did not show clinical or metabolic differences with patients under the regular thrice weekly regimen, except for residual diuresis which was better conserved in the twice-weekly group of patients [19]. In this setting, a prescription of a KA/EAA-supplemented very low protein diet may be considered to be an effective diet for maintaining a twice-weekly hemodialysis regimen for some more months and delay the loss of residual renal function [19], as it has also been reported in patients receiving peritoneal dialysis [20].

\section{Nutritional supplement during maintenance dialysis}

It has been suggested that KA/EAA supplements might be considered for maintenance dialysis patients who present with protein energy wasting [21]. It has been showed that nutritional support, either enteral or intravenous, is able to reverse protein-energy wasting in wasted MHD patients [22]. This hypothesis, already suggested by Hiroshige et al. [23] who used branched-chain amino acids, has not yet been addressed by adequate clinical trials using KA/EAA and therefore should be a subject for future research. Preliminary data from a recent Chinese randomized trial in 100 chronic peritoneal dialysis patients, those patients who received KA/EAA supplements displayed reduced inflammatory status and a decreased serum leptin/adiponectin 
ratio as compared with the control group [24]. In addition, reducing protein intake with the addition of KA/EAA supplements, under strict dietary and nutritional assessments may help controlling serum phosphate in countries where limited phosphate binders are available [25, 26].

\section{Conclusion}

Recent reports provide additional information that can be offered to advanced CKD patients, in order to help motivate them to adhere to these low and very low protein diets. These studies also provide additional evidence supporting the safety of these diets. Adherence to a protein-restricted diet can be improved by selecting patients and offering them tailored dietary choices. Taken together, these new research data confirm an overall picture that a low protein diet providing $0.3-0.6 \mathrm{~g} / \mathrm{kg} \mathrm{BW/d}$ with added KA/EAA supplements may improve proteinuria [27] and delays time until dialysis has to be started [28]. The latter most likely occurs because uremic toxicity is reduced.

\section{Abbreviations}

CKD: Chronic kidney disease; ESRD: End-stage renal disease; EAA: Essential amino acids; eGFR: Estimated glomerular filtration rate; KA: Ketoacids; LPD: Low protein diet (usually $0.6 \mathrm{~g}$ prot/kg/d); MHD: Maintenance hemodialysis; SLPD: Supplemented low protein diet; SVLPD: Supplemented very low protein diet; VLPD: Very low protein diet (usually $0.3-0.4 \mathrm{~g}$ prot $/ \mathrm{kg} / \mathrm{d}$ )

\section{Availability of data and materials}

All information supporting the conclusions of this article are included within the article.

\section{Authors' contributions}

All authors participated to the panel discussion and data presentation. All authors participated to the writing and corrections of the manuscript. DF was responsible for the collection of reviews and comments and the paper submission. All authors read and approved the final manuscript.

\section{Competing interests}

This paper is based on an expert meeting held in Wurzburg, Germany, May 10, 2014. All authors received consulting fees from Fresenius Kabi.

\section{Consent for publication}

Not applicable.

\section{Ethics approval and consent to participate}

Not applicable.

\section{Author details}

${ }^{1}$ UCBL, Centre Hospitalier Lyon-Sud, University Lyon, Carmen, Cens, F-69622 Lyon, France. ${ }^{2}$ Division of Nephrology, Huashan Hospital, Fudan University, Shanghai, China. ${ }^{3}$ Department of Parenteral and Enteral Nutrition, Peking Union Medical College Hospital, Beijing, China. ${ }^{4}$ Department Nephrology and Internal Medicine, Dr Carol Davila Hospital of Nephrology, Carol Davila University of Medicine and Pharmacy, Bucharest, Romania. ${ }^{5}$ Division Nephrology, Kaohsiung Medical University Hospital, Graduate Institute of Clinical Medicine, College of Medicine, Kaohsiung Medical University, Kaohsiung, Taiwan. ${ }^{6}$ Division Nephrology and Hypertension, University of California Irvine School of Medicine, Irvine, CA, USA. Deparment Epidemiology, UCLA Fielding School of Public Health, Los Angeles, CA, USA. ${ }^{8}$ Division Nephrology and Hypertension, Los Angeles Biomedical Research Institute at Harbor-UCLA Medical Center, Torrance, CA, USA. ${ }^{9}$ David Geffen School of Medicine at UCLA, UCLA Fielding School of Public Health, Los Angeles, CA, USA. ${ }^{10}$ Nephrology Division, Baylor College of Medicine, Houston, TX, USA. ${ }^{11}$ SS Nephrology, ASOU San Luigi, Departmentt of Clinical and Biological Sciences, University of Torino, Turin, Italy. ${ }^{12}$ Department
Nephrol, Institute Clin Exp Med, Transpl Centre, Prague, Czech Republic. ${ }^{13}$ Service de Néphrologie, CHU de Bordeaux \& Aurad-Aquitaine, Bordeaux, France. ${ }^{14}$ Department Nephrology, Centre Hospitalier Lyon Sud, Chemin du grand revoyet, 69495 Pierre Bénite, France.

Received: 8 January 2016 Accepted: 14 June 2016

Published online: 07 July 2016

\section{References}

1. Thomas B, van Pelt M, Mehrotra R, Robinson-Cohen C, LoGerfo J. An estimation of the prevalence and progression of chronic kidney disease in a rural diabetic cambodian population. PLOS One. 2014;9:e86123.

2. O'Hare AM, Batten A, Burrows NR, et al. Trajectories of kidney function decline in the 2 years before initiation of long-term dialysis. Am J Kidney Dis. 2012:59:513-22.

3. Fouque D, Laville M. Low protein diets for chronic kidney disease in non diabetic adults. Cochrane Database Syst Rev. 2009;8:CD001892.

4. Locatelli F, Del Vecchio L. Protein restriction: a revisited old strategy with new opportunities? Nephrol Dial Transplant. 2014;29:1624-7.

5. Fouque D, Mitch WE. Low-protein diets in chronic kidney disease: are we finally reaching a consensus? Nephrol Dial Transplant. 2015;30:6-8.

6. Aparicio $M$, Bellizzi $V$, Chauveau $P$, et al. Do ketoanalogues still have a role in delaying dialysis initiation in CKD predialysis patients? Semin Dial. 2013;26:714-9.

7. Piccoli GB, Ferraresi M, Deagostini MC, et al. Vegetarian low-protein diets supplemented with keto analogues: a niche for the few or an option for many? Nephrol Dial Transplant. 2013;28:2295-305.

8. Paes-Barreto JG, Silva MI, Qureshi AR, et al. Can renal nutrition education improve adherence to a low-protein diet in patients with stages 3 to 5 chronic kidney disease? J Ren Nutr. 2013;23:164-71.

9. Piccoli GB, Deagostini MC, Vigotti FN, et al. Which low-protein diet for which CKD patient? An observational, personalized approach. Nutrition. 2014;30:992-9.

10. Mennini FS, Russo S, Marcellusi A, Quintaliani G, Fouque D. Economic effects of treatment of chronic kidney disease with low-protein diet. J Ren Nutr. 2014;24:313-21.

11. Garneata L, Stancu A, Dragomir D, Stefan G, Mirescu G. Ketoanaloguesupplemented vegetarian very low-protein diet and CKD progression. J Am Soc Nephrol. 2016;27(7):2164-76.

12. Piccoli GB, Leone F, Attini $R$, et al. Association of low-protein supplemented diets with fetal growth in pregnant women with CKD. Clin J Am Soc Nephrol. 2014;9:864-73.

13. Cooper BA, Branley $P$, Bulfone $L$, et al. A randomized, controlled trial of early versus late initiation of dialysis. N Engl J Med. 2010;363:609-19.

14. Duenhas M, Goncalves E, Dias M, Leme G, Laranja S. Reduction of morbidity related to emergency access to dialysis with very low protein diet supplemented with ketoacids (VLPD + KA). Clin Nephrol. 2013:79:387-93.

15. Nesrallah GE, Mustafa RA, Clark WF, et al. Canadian Society of Nephrology 2014 clinical practice guideline for timing the initiation of chronic dialysis. CMAJ. 2014;186:112-7.

16. Vanholder R, Lameire $N$, Annemans $L$, Van Biesen W. Cost of renal replacement: how to help as many as possible while keeping expenses reasonable? Nephrol Dial Transplant. 2015. doi:10.1093/ndt/gfv233.

17. Kalantar-Zadeh K, Unruh M, Zager PG, et al. Twice-weekly and incremental hemodialysis treatment for initiation of kidney replacement therapy. Am J Kidney Dis. 2014:64:181-6.

18. Caria S, Cupisti A, Sau G, Bolasco P. The incremental treatment of ESRD: a low-protein diet combined with weekly hemodialysis may be beneficial for selected patients. BMC Nephrol. 2014;15:172.

19. Zhang $M$, Wang $M$, Li H, et al. Association of initial twice-weekly hemodialysis treatment with preservation of residual kidney function in ESRD patients. Am J Nephrol. 2014:40:140-50.

20. Jiang N, Qian J, Sun W, et al. Better preservation of residual renal function in peritoneal dialysis patients treated with a low-protein diet supplemented with keto acids: a prospective, randomized trial. Nephrol Dial Transplant. 2009:24:2551-8.

21. Fouque D, Kalantar-Zadeh K, Kopple J, et al. A proposed nomenclature and diagnostic criteria for protein-energy wasting in acute and chronic kidney disease. Kidney Int. 2008:73:391-8.

22. Cano NJ, Fouque D, Roth $\mathrm{H}$, et al. Intradialytic parenteral nutrition does not improve survival in malnourished hemodialysis patients: a 2-year multicenter, prospective, randomized study. J Am Soc Nephrol. 2007;18:2583-91. 
23. Hiroshige K, Sonta T, Suda T, Kanegae K, Ohtani A. Oral supplementation of branched-chain amino acid improves nutritional status in elderly patients on chronic haemodialysis. Nephrol Dial Transplant. 2001;16:1856-62.

24. Dong J, Li YJ, Xu R, Ikizler TA, Wang HY. Ketoacid Supplementation Partially Improves Metabolic Parameters in Patients on Peritoneal Dialysis. Perit Dial Int. 2015;35(7):736-42.

25. Li H, Long Q, Shao C, et al. Effect of short-term low-protein diet supplemented with keto acids on hyperphosphatemia in maintenance hemodialysis patients. Blood Purif. 2011;31:33-40.

26. Chen J. Nutrition, phosphorus, and keto-analogues in hemodialysis patients: a Chinese perspective. J Ren Nutr. 2013;23:214-7.

27. Mou S, Li J, Yu Z, Wang Q, Ni Z. Keto acid-supplemented low-protein diet for treatment of adult patients with hepatitis B virus infection and chronic glomerulonephritis. J Int Med Res. 2013;41:129-37.

28. Mircescu G, Garneata L, Stancu SH, Capusa C. Effects of a supplemented hypoproteic diet in chronic kidney disease. J Ren Nutr. 2007;17:179-88.

Submit your next manuscript to BioMed Central and we will help you at every step:

- We accept pre-submission inquiries

- Our selector tool helps you to find the most relevant journal

- We provide round the clock customer support

- Convenient online submission

- Thorough peer review

- Inclusion in PubMed and all major indexing services

- Maximum visibility for your research

Submit your manuscript at www.biomedcentral.com/submit
Biomed Central 